\title{
LAS METRÓPOLIS LATINOAMERICANAS EN EL CONTEXTO DE LA GLOBALIZACIÓN: las mutaciones de las áreas centrales
}

\section{Pablo Ciccolella *}

*Geógrafo. Doutor em Geografia, Ordenamento Territorial e Urbanismo (Université de la Sorbonne Nouvelle - Paris III, 2003). Diretor do Programa de Desarrollo Territorial y Estudios Metropolitanos (PDTEM) do Instituto de Geografía da Universidad de Buenos Aires. Professor Titular Regular da Facultad de Filosofía y Letras (FFYL) da Universidad de Buenos Aires (Argentina). E-mail: pjvescovo@yahoo.com.ar

Recebido em 08/2016. Pulicação em 09/2016.

Versão online publicada em 06/2018 (http://seer.ufrgs.br/paraonde)

\begin{abstract}
Resumo - O artigo trata das metrópoles latino-americanas na era da globalização, dos impactos espaciais deste processo sobre as metrópoles, especialmente sobre suas áreas centrais. São analisados os processos de desconcentração e reconcentração metropolitana e a dispersão (difusão) da metrópole sobre o território. É feita uma crítica ao discurso da globalização e da competição entre cidades. É tentado um esforço de interpretação da metropolização na América Latina “a partir do Sul”. Desta forma, são destacadas diferentes linhas de pesquisa que tratam da subjetividade e da identidade urbana, do discurso da sustentabilidade urbana e da análise da informalidade na produção do espaço urbano latino-americano. A modernização neoliberal-pós-moderna e o pensamento único globalista sobre a cidade latino-americana são criticados. Propõe-se abordar questões como os múltiplos vínculos entre pobreza, marginalidade, medo, violência e narcotráfico nos estudos urbanos e metropolitanos latino-americanos. De igual modo, na evolução das áreas centrais considera-se a rede de centros e subcentros que constituem um espaço de controle que insere as metrópoles na rede mundial de cidades. Nas conclusões é apresentada uma agenda de pesquisa que discute a necessidade construir um discurso, conceitos e instrumentos analíticos e operativos alternativos que possam evitar o chamado "pensamento único" sobre a cidade e o planejamento urbano na América Latina.
\end{abstract}

Palavras-chave: o globalização; metrópole latino-americana; áreas centrais; agenda de pesquisa urbana. .

Resumen - El artículo trata de las metrópolis latinoamericanas en la era de globalización, de los impactos espaciales del proceso de globalización sobre las metrópolis, especialmente sobre sus áreas centrales. Son analizados los procesos de desconcentración y reconcentración metropolitana y la dispersión (difusión) de la metrópoli sobre el territorio. Se hace una crítica al discurso de la globalización y de la competencia entre ciudades. Se intenta un esfuerzo de interpretación de la metropolización en América Latina "desde el Sur". Así son destacadas diferentes líneas de investigación que tratan de la subjetividad y de la identidad urbana, del discurso de la sustentabilidad urbana y el análisis de la informalidad en la producción del espacio urbano latinoamericano. La modernización neoliberal-posmoderna y el pensamiento único globalista sobre la ciudad latinoamericana son criticados. Se propone abordar cuestiones como las múltiples vinculaciones entre pobreza, marginalidad, miedo, violencia y narcotráfico en los estudios urbanos y metropolitanos latinoamericanos. Igualmente, en la evolución de las áreas centrales se considera la red de centros y subcentros que constituyen un espacio de control que inserta las metrópolis en la red global de ciudades. En las conclusiones se presenta una agenda de investigación planteando construir un discurso, concep $\neg$ tos e instrumentos analíticos y operativos alternati $\neg$ vos que puedan evitar el llamado "pensamiento único" sobre la ciudad y la planificación urbana en América Latina.

Palabras clave: globalización; metrópoli latinoamericana; áreas centrales; agenda de investigación urbana.

\section{Consideraciones preliminares}

Luego de treinta años de transformaciones aceleradas en las principales metrópolis latinoamericanas, el resultado parece ser el agravamiento de una estructura socio-económica-territorial históricamente desigual.

La reestructuración económica mundial iniciada a mediados de los '70 conjuntamente con las transformaciones políticas, sociales, tecnológicas y culturales han provocado el progresivo debilitamiento de los Estados nacionales. Las sucesivas políticas de ajuste, racionalización y modernización, han ido desarticulando las estructuras burocrático administrativas y los marcos regulatorios construidos durante la etapa del Estado de Bienestar. En el marco de la globalización económica, las economías nacionales y los intereses regionales han quedado supeditados a las decisiones supranacionales y a una mayor libertad de acción del capital.

En las grandes ciudades, los cambios tecnológicoproductivos, político institucionales y socio-culturales 
se han expresado en términos físicos de modo muy definido y extendido, en los procesos de densificación de áreas centrales y pericentrales y en la expansión casi ilimitada de los suburbios bajo tipologías diversas de urbanizaciones cerradas (UC). La proliferación de grandes superficie comerciales y centros de ocio suburbanos sumado a la ampliación de la red de autopistas en torno a la ciudad, han convergido en la producción de este nuevo tipo de ciudad, dando lugar a lo que se conoce en la literatura urbana reciente como metápolis (Ascher, 1995), ciudad difusa (Indovina, 1990); ciudad dispersa (Monclús, 1998) o ciudad sin confines (Nel.lo, 1998).

Como resultado del sesgo desconcentrador de los años ochenta y las tendencias remetropolizadoras de los noventa, con un patrón de urbanización sumamente abierto, la ciudad parece disolverse sobre los territo- rios que antes denominábamos hinterland (Ciccolella, 2003).

Existe de hecho una gran dificultad por denominar los productos urbanos de esta etapa, y de caracterizar a la misma metrópolis que surge de estos procesos contradictorios, evidenciada en la aparición de numerosos neologismos como ciudad global, ciudad informacional, megaciudades, metápolis, ciudad difusa, ciudadred, ciudad sin confines, ciudad genérica, etc.

Mas allá de semejanzas y diferencias de cada metrópolis, el modelo de gestión política y económica do- minante en los años noventa y a principios de la década actual -que, definitivamente se desprende del consenso de Washington y se ha popularizado como neoliberal-, ha tendido a permitir no sólo mayor fluidez del capital, sino mayor libertad de acción al mismo como ordena- dor territorial, poniendo en crisis la relación entre la esfera de lo público y la esfera de lo privado, evidenciando una indudable tendencia al incremento de esta última. Parafraseando a Carlos Vainer, el ocaso de las rigideces entre ambas esferas ha permitido el avance del capital sin mayores mediaciones en los procesos de decisión y ejecución de las políticas territoriales, pero sobre todo, la instauración de una influencia creciente del capital privado - especialmente el de carácter global, concentrado y oligopólico - sobre las transformaciones del territorio. Esta vigorosa y agresiva arremetida del capital sobre el espacio urbano trastoca la propia naturaleza del mismo y condiciona a la propia ciudad como un todo.

En palabras de Ana Fani Alessandri:

nesse contexto, a terra e o solo urbano mudam de sentido: passam dos usos improdutivos destinados à plena realização da vida urbana - para os usos produtivos- os lugares como condição da reprodução económica - e do consumo no espaço para o consumo do espaço. (2008, pág. 51)

El predominio del capital sobre el Estado y de lo privado sobre lo público han dado lugar a la competencia interurbana, es decir, a que las ciudades compitan entre sí, y, por lo tanto, a la necesidad de desarrollo de atributos para dotarse de ventajas en esa puja, en el marco de una economía de tendencias marcadamente globalizadoras. Una de las más evidentes y claras expresiones de estas tendencias a nivel de instrumentos y planes urbanísticos, está constituida por el denominado marketing urbano, que consiste en un conjunto de políticas tendientes a dotar a la ciudad de una imagen y de unas infraestructuras y atractivos en materia de calidad de vida y de "ambiente de negocios" que las coloque en condiciones de competir con otras ciudades para atraer inversiones extranjeras.

Esta relativa "ausencia" o incapacidad del Estado local para "controlar" y regular el territorio, ha dado como resultado un mayor espacio de libertad del capital inmobiliario y financiero para actuar sobre el espacio urbano rediseñándolo según sus necesidades y apetencias de renta urbana, llevando adelante de manera quizá más acentuada que en otras etapas del capitalismo, lo que podríamos denominar un proyecto hegemónico de ciudad, transformándose así en el factor de desarrollo urbano más decisivo o de mayor poder transformador. La acción del poder económico tiende a desmontar la metrópolis en fragmentos de ciu- dad o de barrios con una lógica cada vez más selectiva y acelerada, destruyendo viejos órdenes territoriales y construyendo otros nuevos según sus lógicas de reproducción.

La ciudad como ámbito vivencial, de encuentro, de sociabilidad, de articulación social y solidaria, ha cedi- do demasiado espacio a la valorización capitalista exacerbada, a la lógica territorial de la economía global, al avance sobre el espacio público. El territorio urbano, su base económica y sus instituciones políticas se distancian cada vez más de la gente, se dessocializan, deshumanizan y despersonalizan, alienando identidades y derribando derechos esenciales, como el derecho a la ciudad del que nos hablaba H. Lefèbvre. El ciudadano parece quedar en segundo plano.

Carlos de Mattos, responsabiliza decisivamente a las mutaciones del sistema capitalista, como causantes de las transformaciones territoriales urbano-metropolitanas, aunque rescata que las ciudades latinoamericanas, sin embargo conservan en mayor o menor medida rasgos identitários que no fueron necesariamente barridos por la globalización, siendo "... cada ciudad una 
experiencia y una conformación única e irrepetible". Según el mismo autor, esta condición de las ciudades latinoamericanas compromete seriamente la posibilidad de desandar este camino de construcción de las metrópolis latinoamericanas:

En la medida en que los objetivos de una determinada propuesta de gestión urbana suponga una modificación estructural de las tendencias ... su cumplimiento habrá de requerir necesariamente la conformación de otro escenario, sustantivamente distinto al que se ha formado bajo los impulsos de la liberalización, la globalización y la informa- cionalización, lo que obviamente está fuera de las atribuciones y posibilidades de los planificadores y de los gobiernos urbanos o locales (Mattos, 2008).

Compartimos parcialmente esta indicación, pero entendemos que se abre un espacio de posibilidad en otros niveles de gestión superiores Queda claro que el modelo de desarrollo urbano elitista, consumista y neoliberal ha fracasado rotundamente como modelo superador de las desigualdades a la par que ha tenido un éxito rotundo en afirmar los intereses de las minorías privilegiadas de los factores de poder mundial. La Planificación Estratégica, sucesora del modelo burocrático-centralizado-autoritario, si bien es de origen progresista y promueve contenidos y modalidades de planificación participativa, termina volviéndose a menudo reaccionaria, elitista y excluyente, sino ineficaz.

Lamentablemente hay mas casos de asociación de la planificación estratégica con el marketing urbano y la gentrificación que con una genuina democratización de los usos del suelo urbano y el desarrollo urbano integral e integrador. En algunos casos, especialmente en el ámbito latinoamericano, la planificación estratégica ha fortalecido la posición del capital especulativo y ha permitido al decir de Otília Arantes, una convergencia entre especuladores, funcionarios y desarrolladores urbanos, al promover un tipo de gestión del espacio urbano que termina estando prioritariamente al servicio de las elites (Arantes: 2000: 32).

Frente a estas transformaciones tanto físicas (cambios morfológicos, estructurales y de infraestructuras de la ciudad) como sociopolíticas y culturales (cambios a nivel del papel del Estado, nuevos actores económicos y sociales, nuevas pautas de consumo del suelo urbano y de las funciones de la ciudad), es necesario retomar la discusión sobre la naturaleza de la ciudad y particularmente de los grandes espacios metropolitanos.

\section{Algunas claves para pensar la ciudad latinoameri- cana desde diversas perspectivas}

El propio discurso académico parece estar en un callejón sin salida. Las reflexiones se han estancado en torno al discurso y a los relatos de la globalización y de la competitividad de nuestras ciudades. Es necesaria una reflexión desde el sur, que vaya más allá de estos "chalecos de fuerza", profundizando sobre las nuevas formas de fractura socio-territorial, desmitificando la narrativa política, mediática y científica falaz que extiende al conjunto de nuestras metrópolis, la experiencia "exitosa" de algunos fragmentos de nuestras ciudades.

Algunos autores nos proporcionan elementos analíticos críticos para salir de esta encerrona. Por ejemplo, para Alicia Lindon (2001, p. 55) revaloriza la subjetividad y la identidad como claves analíticas de la ciudad latinoamericana actual.

\begin{abstract}
...no es posible estudiar la subjetividad y la identidad en nuestras metrópolis múltiples, sin considerar la cotidianidad, la vida práctica, el hacer del individuo, ya que es en ella en donde emergen las identidades y la subjetividad social, los fragmentados imaginarios; es en ella en donde el científico social, encuentra su campo de observación más promisorio. Así revalorizamos analíticamente al sujeto visto desde su subjetividad y su hacer cotidiano y banal, para acercar- nos a estudiar las metrópolis actuales...En última instancia, de nuestro razonamiento se deriva la necesidad de estudiar los modos, estilos y géneros de vida para comprender las metrópolis actuales...
\end{abstract}

Desde el análisis crítico a los postulados sobre la ciudad sostenible o la ambientalización del discurso sobre el desarrollo urbano, Henri Acselrad (2001, p. 21-25) nos aporta que:

Uma tal abordagem (modernização ecológi- ca
das cidades) é em esencia, compatível com o
chamado "pensamento único urbano" que exi-
ge das cidades que se ajustem aos propósitos
tidos por enelutáveis da globalização financei-
ra. A chamada "inserção competitiva" é, neste
ideario, evocada para presiona-las a se trasns-
formarem em espaços autônomos em disputa
- inclusive pela via da afirmação de seus atri-
butos "ambientais". A cidade do "pensamento
único" é consecuentemente, a cidade do "am-
biente único", o ambiente dos negócios.

Sin embargo, lamentablemente, los hechos parecen ir en un sentido contrario. El sistema capitalista actual se ha transformado en un tipo de capitalismo que podríamos denominar capitalismo metropolitano, en tanto que el capital se realiza a través del territorio urbano-metropolitano y en la medida en que el capital privado aparece como ordenador territorial preponde- 
rante basándose en los múltiples recursos o ventajas competitivas de cada porción del territorio, extrayendo las plusvalías más cuantiosas precisamente de las singularidades, y especificidades que hacen de cada territorio el lugar óptimo para cada tipo de producción. Por otra parte, como sostiene David Harvey, el capitalismo actual compra influencia política y es constitutivamen- te corrupto y corruptor en términos políticos (HARVEY, 2007, p. 24).

Precisamente, el factor central de los cambios económicos, sociales, políticos, culturales y territoriales urbanos parece ser una convergencia entre los avances científico-tecnológicos, una nueva fase de explotación extrema de la fuerza de trabajo y la capacidad del capital para comprar influencia política. En algún sentido, este capitalismo metropolitano, se parece a las formas más primitivas del capitalismo del siglo XVIII, ya que, siempre según David Harvey, está desarrollando formas inmorales y criminales de acumulación por desposesión (HARVEY, 2006, p. 41 y ss).

La transformación de grandes ciudades en centros financieros globales como Nueva York, Londres, Tokio, Frankfurt, y, en un futuro próximo, seguramente también Sao Pablo, Santiago, México, Buenos Aires, Shangai, Mumbai, El Cairo, etc., va haciendo progresivamente imposible a los sectores populares y ciertas clases medias vivir en los núcleos centrales de las grandes conur- baciones.

El dinero especulativo financiero-inmobiliario esta "comprando" los mejores lugares de las ciudades $\mathrm{y}$ convirtiéndolas en gigantescos condominios cerrados y desplazando hacia las periferias más hostiles no sólo a los pobres sino también a los sectores medios. Esto es ya una realidad tangible en Nueva York y Londres y una tendencia cierta en las principales ciudades del mundo y de América latina. Las clases medias altas y altas se han ido apropiando a la vez de los mejores lugares del suburbio, o mejor dicho de suburbios -paraísos artificiales que han construido como bunker de resistencia cultural y oasis de seguridad y calidad de vida-; y a la vez están volviendo al centro, apropiándose también de los mejores lugares para el consumo de objetos y bienes culturales, en las burbujas internacionales y turistificadas de las áreas centrales de la ciudad, de donde también están expulsando a los pobres en esos obscenos procesos que tanto hemos estudiado bajo el benévolo y neutro eufemismo de la gentrificación...

Esto representa un gran problema y desafío intelectual, político y metodológico. Ya no es sólo la clase trabajadora, en términos clásicos, la que está siendo desposeída y desplazada. Las izquierdas políticas y académicas deberían prestar más atención a estos nue- vos fenómenos, relativizando los conceptos clásicos e intentando acumular energía para unificar los diferen- tes movimientos sociales y las formas de resistencia y lucha.

Lo realmente importante es que nuestras ciudades sean buenos lugares para vivir. Me niego a creer que el statu quo de la globalización y el capitalismo global tal como estaba diseñado hasta setiembre de 2008, constituya la única forma de seguir moldeando nuestras ciudades en un sendero de crecimiento y desarrollo urbano. Particularmente porque el capitalismo está mutando nuevamente, pero sobre todo porque definitivamente -y, en esto soy muy terso y poco científico, quizá- no puede concebirse el desarrollo urbano con la creciente marginalización de las mayorías o de las crecientes minoría pobres en la ciudad. Sin duda, tenemos un compromiso ético con la realidad, con la búsqueda de la mejor aproximación a la verdad desde los métodos científicos, pero estos, a veces están condicionados por nuestros posicionamientos ideológicos conscientes o inconscientes. Pero, por otro lado, también como intelectuales, pensadores o científicos, tenemos otro compromiso ético y moral e ideológico, que es el compromiso con el derecho a la ciudad, con una ciudad para todos, con la búsqueda de propuestas para ayudar, aún modestamente a construir ciudades cada vez más democráticas, integradoras solidarias e inclusivas.

La ciudad global en América latina sólo está representada por ciertos fragmentos privilegiados de la ciudad que el discurso político, el de los media, y aún a veces - como ya sugerimos más arriba-, el propio discurso académico mistifica por el conjunto de la ciudad. La ciudad ha sido insistentemente estudiada a través de una paradigma que podría denominarse "la geografía urbana de la riqueza y la competitividad" y eso no está mal, necesitamos el conocimiento sobre la producción elitista y neoliberal de la ciudad. El problema es que se han vuelto alarmantemente minoritarios los trabajos sobre la geografía de la pobreza urbana, al mismo tiempo que "...los procesos de la urbanización informal, que marcaron la configuración de la ciudad latinoamericana, siguen constituyendo un porcentaje mayoritario del espacio construído y, por otra parte, en aumento en las últimas décadas (Montoya, 2006, pág.65).

Proceso que también constatan numerosos estudios de investigadores como Nora Clichevsky, Mariana Fix, Pedro Abramo y tantos otros investigadores latinaomericanos. En fin, gran parte del suelo urbano en AL ha sido ocupado a partir de una lógica de la necesidad y de relaciones informales de mercado. Ciudades como Lima, hoy están estructuradas en un porcentaje mayoritario de su espacio a partir de la consolidación 
de las llamadas barriadas, como paisaje urbano dominante de la ciudad y que, en su evolución a partir de sus múltiples formas de inserción en la economía y en la sociedad global, se identifican a si mismas, y por ende a la propia ciudad de Lima como un todo, como una Globalbarriada, según la sugerente expresión de Wiley Ludeña.

La ciudad debe ser privilegiada y concebida como un lugar de socialización, de trabajo, de producción y de reproducción, no preferentemente como un lugar de lucro, de producción de plusvalías cada vez más cuantiosas, o unos lugares donde la competitividad es la va- riable excluyente del desarrollo urbano, lo que tiende a fracturar a nuestras metrópolis entre sí, en lugar de generar una red de ciudades solidarias en su desarrollo social y productivo.

Podemos pensar así, en una ciudad latinoamericana, que tiene un gigantesco capital cultural, simbólico, humano, moral, natural y material; que hace aún de nuestras ciudades lugares no irremediablemente destruidos, corrompidos, corroídos, erosionados, por el avance de un tipo de modernidad y de modernización desestructuradora, agresiva y desterritorializadora. Felizmente, la modernización neoliberal-posmoderna, esa modernidad liquida de Bauman, no llegó a todos los lugares de la ciudad latinoamericana.

Barrios enteros de la ciudad, a la vez han sido marginados por ese tipo de modernización y en algún sentido son el germen de la resistencia a la misma y el testimonio de que algo funciona muy mal en nuestras ciudades y en el crecimiento económico de nuestros países, por cuanto los procesos de fragmentación, segregación y marginación urbana no sólo no se solucionan con ese tipo de crecimiento sino que la brecha entre distintos lugares de la ciudad están en aumento.

Apocalíptico, y derrotado, Zygmunt Bauman nos dice que:

\begin{abstract}
Además el mundo está agotado. No quedan lugares por descubrir, ni lugares para ocultarse del orden imperante (o, para el caso, del desorden y del desgobierno) En este mundo ya no hay "afuera". Las ciudades no son más que una pálida sombra de lo que eran los reinos soberanos, pero, il n'y a pas hors de cité, no hay ningún lugar fuera de la ciudad, en ninguna parte del mundo. La "utopía", en su significado original de un lugar que no existe, se ha convertido en la lógica del mundo globalizado, en una contradicción en los términos. Ese "no-lugar", ya no es un lugar. La "u" de "utopía" desahuciada por el topos, se volatiliza, pierde toda esperanza de echar raíces, de "reinsertarse". (2002, pág. 288)
\end{abstract}

Por el contrario, Richar Sennett "vé" la historia del futuro con ojos más optimistas:

\begin{abstract}
Un nuevo orden del poder obtenido a través de una cultura cada vez más superficial. Puesto que la gente sólo puede afirmarse en la vida tratando de hacer algo bien por el sólo hecho de hacerlo bien, el triunfo de la superficialidad en el trabajo, en las escuelas y en la política me parece frágil. Tal vez la rebelión contra esta cultura debilitada con- stituya nuestra próxima nueva página de la historia (2006, pág. 167).
\end{abstract}

Parece que estamos obligados a potenciar la imaginación geográfica para salir de la encerrada de las miradas apocalípticas, pesimistas, sin propuesta para la salida de la dramática problemática urbana y a insistir sobre la riqueza del concepto de territorio y este aplicado a las especificidades de la ciudad y la metrópolis. Habrá que abordar también con mayor insistencia cuestiones como las múltiples vinculaciones entre pobreza, marginalidad, miedo, violencia, narcotráfico, que requieren de mucho más espacio en el marco de los estudios urbanos y metropolitanos. Ha habido algunos valiosos esfuerzos pioneros, como los de Lia Osorio Machado y un estudio sumamente interesante y reciente de Marcelo Lopes de Souza (2008) que desarrolla el concepto de Fobópolis, es decir, una ciudad dominada por el miedo a la criminalidad violenta, según el propio autor. Varios trabajos, también recientes de sociólogos como Mike Davis (Control urbano: la ecología del miedo, City of Quartz, o Planet of Slums) o de LoîcWacquant (Los condenados de la Ciudad), muestran la complejidad, la riqueza y la necesidad de más y mejores estudios sobre estas temáticas en clave territorial urbana y metropolitana.

\section{La evolución de las áreas centrales}

Las constantes innovaciones en materia de sistematización y difusión de la información, potenció la importancia estratégica de los procesos de toma de decisiones, $\mathrm{y}$, paradójicamente se tornó el principal factor del proceso de reconcentración territorial del poder económico. Según Kohn Cordeiro "a pesar de la telemática, los momentos de toma de decisiones, las discusiones sobre investigaciones científicas, el intercambio de asuntos confidenciales de negocios se realizan cara a cara" (Kohn Cordeiro, 1993: 324). Tanto Sassen como Veltz arriban a conclusiones similares al intentar explicar cuales son los factores del resurgimiento reciente de los centros de las grandes metrópolis o de la creación de nodos alternativos, dentro de la estructura territorial metropolitana. En ese proceso se crean equipamientos compatibles con 
la expansión de la Ciudad Corporativa. (Ciccolella, 1999: 8).

Entre la multiplicidad de funciones que cumplen las áreas centrales de las grandes metrópolis, o Ciudad Corporativa, está la de alojar las casas centrales de las principales entidades bancarias locales y globales. Estas cumplen un papel destacado en el proceso de circulación del capital, contribuyendo a incrementar el carácter de nodo de gestión económica y del poder económico a las ciudades donde se aglomeran, y en particular, a los espacios centrales de las mismas (Lobato Correia, 1993: 163).

La problemática de la centralidad respecto de las metrópolis implica un análisis a doble escala (Alessandri Carlos, 2001:178). La escala de la propia región metropolitana como centro o como nodo de un sistema de ciudades y territorios a los que se conecta, o que a veces comanda; y la escala del núcleo central de la aglomeración donde se observa la mayor cantidad y densidad de funciones de comando (sedes empresariales, sedes financieras, servicios avanzados, hotelería internacional, centros políticos, centros culturales, etc.).

Paralelamente, la centralidad hoy debe ser estudiada en una doble dimensión, la clásica, donde predomina el elemento físico, la contigüidad espacial, la aglomeración física de objetos emblemáticos del poder económico (bancos, sedes empresariales, edificios inteligentes) y la dimensión reticular, donde los vínculos predominantes son inmateriales (por medio de las tecnologías de comunicación e informática) y pertenecen al campo de las múltiples relaciones interempresaria-les, las solidaridades entre grandes corporaciones, en fin, la pertenencia a un mismo espacio relacional, más allá de todo hiato o discontinuidad territorial intrametropolitano $o$ intermetropolitano.

En este sentido, revisitar la cuestión de la centralidad, no es en absoluto ocioso, porque se han verificado transformaciones arquitectónicas, urbanísticas y territoriales que denuncian un nuevo tipo de organización territorial del poder económico. No basta la dimensión territorial zonal para definir la nueva naturaleza de la centralidad, y de hecho, aún en un plano en el que se puede rescatar la dimensión regional, aquella se ha vuelto polinuclear, a la manera parisina, londinense, santiaguina o paulista, con operaciones urbanísticas colosales que han desplazado considerablemente la centralidad clásica, en términos físicos, o bien, una polinuclearidad tenue que no afecta la hegemonía y expansión de la centralidad clásica, transformándola en un corredor corporativo, a la manera porteña, caso que se expone en este estudio.

En síntesis, hablar hoy de centralidad implica, como decíamos, por un lado, la delimitación de una zona de concentración de equipamientos, funciones y actividades vinculadas al comando de la economía regional, nacional y a la vinculación con la red de comando económico del capitalismo global. Lo que hemos denominado anteriormente, distritos de comando (Ciccolella, 1999: 17).

Por otro lado, la definición de la centralidad, implica considerar la red completa de centros y subcentros que constituyen un único espacio de control transaccional y corporativo, que constituye el nodo completo que se inserta en la red global de toma de decisiones. Es decir, yuxtapuestos o no, la forma polinuclear de la centralidad o su morfología tipo corredor corporativo constituye en cualquier caso un único espacio de comando, a veces liderados por un área central más potente que otras, como es el caso porteño, que se inserta en la red de ciudades globales o nodos de control de la economía global.

\section{Conclusiones y agenda}

Las transformaciones estructurales, morfológicas, tecnológicas, productivas, culturales, urbanísticas y socioterritoriales experimentadas por las grandes metrópolis latinoamericanas no deben ser "naturalizadas" ni consideradas una fatalidad o algo irreversible, necesario e inevitable. La ciudad siempre es un espacio vivo y mutante cuyas concreciones deben apuntar a mejorar la calidad de vida del conjunto de la comunidad que en ella habita, y ello puede implicar ajustes y cambios de rumbo considerables en el modelo territorial, en el proyecto de ciudad y en los principales elementos de infraestructura que le dan materialidad.

Nuestros territorios urbanos aparecen así como desafíos, lugares y momentos, donde los actores no he- gemónicos pueden emerger y resignificar los caminos de desarrollo urbano y presionar para un cambio de orientación no sólo del Estado local sino también del Estado nacional y su retorno como agente ordenador y planificador de un espacio urbano para todos.

El desafío es cómo construir un discurso, conceptos e instrumentos analíticos y operativos alternati- vos que puedan evitar el "canto de sirena" del llamado "pensamiento único" sobre la ciudad y la planificación urbana. Tal como señala Pedro Abramo en "La Ciudad Caleidoscópica" (2008, pág. 329):

Si fue preciso recorrer un camino tan largo 
para llegar a la solución - finalmente bien simple - del retorno a la regulación y a la política intervencionista en lo urbano, es porque ha sido necesario develar los trazos perversos que la miopía del liberalismo urbano persiste en mantener en la oscuridad. Es en ese sentido que me posiciono en el campo de la resistencia a un discurso neoliberal urbano que apuesta a una solución de mercado para descubrir el paraíso de la eficiencia, de la creatividad y de la felicidad social.

Me parece que, a esta altura debemos pensar en algunas propuestas bien concretas que unan, reflexión teórica, y clarificación conceptual como antecedentes para diseñar nuevos instrumentos, instituciones y procedimientos de acción sobre el territorio urbano.

En primer lugar me parece que debemos refutar críticamente el concepto de competitividad como único sendero posible al desarrollo e incorporar a nuestros análisis y discursos conceptos igualmente operativos y concretos, pero de significado bien diferente como complementariedad, cooperación y solidaridad entre nuestras metrópolis.

Avanzar más aún en la reelaboración del concepto de espacio-tiempo, vinculado a la problemática concreta del habitar, de la vida cotidiana, de la ciudadanía, de los imaginarios urbanos, de las redes sociales, de los nuevos movimientos sociales y del tejido socioproductivos de nuestras ciudades, y particularmente, el principio lefebvriano del derecho a la ciudad.

Desarrollar también más en profundidad, tanto como concepto, como instrumento, la cuestión de las redes, como realidad de estructuración territorial, como constructo en términos de infraestructura, pero también como vehículo de mejoras en la producción y en la estructuración de tejidos de organizaciones socia- les y de vínculos productivos.

Potenciar múltiples y creativos abordajes sobre la problemática de la desigualdad, la pobreza, el poder, la violencia urbana y los distintos circuitos de la economía urbana.

Resignificar y jerarquizar el papel que juegan la producción y el trabajo en la ciudad como factores de construcción material y simbólica de la ciudad.

Yo creo que están dadas hoy algunas precondiciones básicas para pensar desde otro lugar el desarrollo urbano:

- El actual contexto de crisis que parece haber der- ribado la inercia del Consenso de Washington y que condiciona la continuidad de la Globalización, al me- nos, en los términos como la conocíamos hasta ahora.

- Un mayor involucramiento del Estado
Nacional, no solo a través de los llamados salvatajes financieros y empresariales, sino también, recuperando su papel de gran inversor, no solo en infraestructuras que generan procesos de valorización del capital sin mayores captaciones de plusvalías urbanas, sino fundamentalmente

- y quizá a partir del desarrollo intensivo de estas, en infraestructura social, donde la vivienda, la educación, la salud, la investigación científica, el desarrollo tecnológico y particularmente la economía del conocimiento se constituyan a la vez en un círculo virtuoso de justicia socioterritorial y genuino desarrollo económico y productivo, al servicio de la sociedad toda.

- Estas tendencias y posibilidades se potencian en AL y aún más en Sudamérica y más aún en el MERCO- SUR ampliado. Incluso hasta el G-20 parece dispuesto a un nuevo consenso a partir del cual la Globalización

- insisto, ya no conservará probablemente todas las inercias y tendencias que conocíamos hasta ahora. No morirá, sin duda, pero insisto, ya no será la misma y eso abre una enorme ventana de oportunidad para nues- tros pueblos y nuestras ciudades.

- La defensa de la democracia a escala continental, el UNASUR como germen institucional

- La creación de instituciones financieras alterna- tivas (Banco del Sur, p.ej.)

- También podemos pensar seriamente en un creciente involucramiento del Estado en todas sus escalas de gestión, pero donde la dimensión nacional o federal, e incluso la transestatal, en el caso del Mercosur, permita superar las limitaciones que los estados locales tienen, como bien dice de Mattos, en gestionar un cambio de rumbo en la producción de la ciudad, que aquella otra escala de Estado si podría acometer, de mantener- se y potenciarse los acuerdos transgubernamentales actuales en AL, más allá de las suspicacias o dudas que algunas experiencias en curso nos pueden suscitar, incluyendo los gobiernos que no están enrolados en una experiencia progresista, como puede ser hoy aún el caso de Colombia o México.

Pero también existen algunas esperanzas significativas, más allá de los desafíos, peligros y conflictos señalados. Quizá la esperanza más relevante sea la revitalización de la sociedad civil a través de movimientos sociales clásicos o la proliferación de nuevos movimientos y organizaciones sociales de base territorial o temática comprometidos e involucrados en proyectos autogenerados para un barrio o una ciudad mejor para todos.

En ese marco es destacable una nueva toma de consciencia crítica por parte de los jóvenes, luego 
de una prolongada fase de indiferencia política y de des- creimiento y descompromiso sobre el papel de la política y las luchas sociales en América latina.

Sabemos que en nuestras ciudades tenemos un capital evidente de conocimiento, de creatividad, de inteligencia, de sensibilidad, de esa condición que hace vino del agua y multiplica panes y peces; ese milagro no bíblico sino real, concreto, contemporáneo y cotidiano: aquel que todos los días hace renacer el orden del caos, la vida de la muerte, la solidaridad de la violencia, la fuerza de la fragilidad, la unidad de la fractura. La ciudad latinoamericana no es ciertamente una ciudad idílica sino contradictoria, enferma pero maravillosamente viva, dinámica aunque desordenada, inmensamente pobre, pero también inmensamente rica...

Dichas "ventajas competitivas" no se consiguen fácilmente en los elegantes centros o suburbios satisfechos de las elites de nuestras ciudades y de aquellas del primer mundo. Ese es un patrimonio del barrio y de las comunidades populares de la periferia de nuestras ciudades latinoamericanas. Esas que no acaso, como tan bien canta Chico Buarque, no figuran en el mapa...

\section{Bibliografía}

ABRAMO, Pedro. A Cidade Caleidoscópica. Rio de Janeiro: Bertrand Brasil, 2008.

ACSELRAD, Henri. A duração das ciudades. Rio de Janeiro: CREA-RJ-DP\&A editora, 2001.

AGUILAR, A. G. Las mega-ciudades y las periferias expandidas. EURE (Santiago), v. 28, n. 85, p. 121-149, dic. 2002 .

ALESSANDRI Carlos, A.F. A urbanização da sociedade: questões para o debate. In: OLIVEIRA, M. P.; COELHO, M. C. N.; CÔRREA, A. de M. (Org.). O Brasil, a América Latina e o Mundo: espacialidades contemporâneas (II). Rio de Janeiro: Lamparina, 2008, v. 2, p. 49-60.

ARANTES, O. Uma estratégia fatal: a cultura nas novas gestões urbanas in: Arantes, O.; Vainer, C.; Maricato, E. (Org). A cidade do pensamento único: desmanchando consensos. Petrópolis: Vozes, 2000, p . 11-73.

ARTIGAS, Alicia et al . Transformaciones socio-territoriales del Área Metropolitana de Montevideo. EURE (Santiago), v. 28, n. 85, p. 151-170, dic. 2002 .

BARRIOS, S. La Caracas metropolitana, de la ciudad compacta a la metrópoli de metropolis. En El desafío de las Áreas Metropolitanas en un mundo globalizado. Una mi- rada a Europa y América Latina. Actas del Seminario Interna- cional, junio de 2002. Barcelona: Institut Catalá de Cooperació Iberoamericana, 2003.
BAUMAN, Z. La sociedad sitiada. Buenos Aires: Fondo de Cultura Económica, 2002.

BAUMAN, Z. Modernidad líquida. Buenos Aires: Fondo de Cultura Económica, 2005.

CARIOLA, C. y LACABANA, M. Globalización y desigualdades socioterritoriales: la expansión de la periferia metropolitana de Caracas. EURE (Santiago), vol. 29, no.87, p. 05-21. Ago 2003.

CARIOLA, C. y LACABANA, M. La metrópoli fragmentada: Caracas entre la pobreza y la globalización. EURE (Santiago), vol.27, no. 80, p. 09-32. Mayo 2001.

Chion, Miriam. Dimensión metropolitana de la globalización: Lima a fines del siglo XX. EURE (Santiago), vol. 28, no. 85 , p. 71-87, Dic 2002.

CICCOLELLA, Pablo. Globalización y dualización en la región metropolitana de Buenos Aires. Grandes inversiones y reestructuración socioterritorial en los años noventa. EURE (Santiago), Vol. XXV - N 76, p. 5-27, dic. 1999.

CICCOLELLA, Pablo y LUCIONI, Nora. La ciudad corporativa. Nueva arquitectura empresarial, redefinición de la centralidad y surgimiento de una red de distritos de comando en la Región Metropolitana de Buenos Aires. In De Mattos, Carlos et. al. (Editores) Gobernanza, Competitividad y Redes: la gestión en las ciudades del siglo XXI. Santiago: Insti- tuto de Estudios Urbanos y territoriales PUC-Chile, 2005, p. 185-209.

CICCOLELLA, Pablo. Metrópolis latinoamericanas: territorios subregulados, espacios del capital? In Aguilar, Adri- án, G. (Coordinador) Las grandes aglomeraciones y su periferia regional. Experiencias en Latinoamérica y España. México: CONACYT- HCD - IG / UNAM - M.A. Porrua Editor, 2006, p.305-324

CICCOLELLA, P. Transformaciones recientes en las metrópolis latinoamericanas. In Fernandez Casó, V. y Gurevich, R. (coord.) Geografía, nuevos temas, nuevas preguntas, Buenos Aires: Ed. Biblos, 2007, p.125.145.

CORDEIRO, H. K. A cidade mundial de São Paulo e o complexo corporativo do seu centro metropolitano. In SCARLATTO, F. C. Et all (org.) Fim de século e globalização. São Paulo: Hucitec/ANPUR, 1993. Coleção O Novo Mapa do Mun- do.

DEMATTEIS, G. Suburbanización y periurbanización. Ciudades anglosajonas y ciudades Latinas. En Monclús, F. (ed.) La ciudad dispersa. Suburbanización y nuevas periferias. Barcelona: Centre de Cultura Contemporánea de Barcelona, 1998, p. 17-33.

De MATTOS, Carlos A. Santiago de Chile, globalización y expansión metropolitana: lo que existía sigue existiendo. EURE (Santiago), vol.25, no.76, p. 29-56, dic 1999.

De MATTOS, Carlos A. Mercado metropolitano de trabajo y desigualdades sociales en el Gran Santiago: ¿Una ciudad 
dual? EURE (Santiago), vol. 28, no.85, p. 51-70, dic 2002.

De MATTOS, C. La tercera revolución urbana en AL, Hacia lo urbano generalizado? Ponencia presentada al X Seminario Internacional de RII y III Taller de la RIER. Querétaro, México, 2008.

GARCIA CANCLINI, N. Culturas Híbridas. Estrategias para entrar y salir de la modernidad. Buenos Aires: Ed. Sudamericana, 1992.

HARVEY, D. Spaces of global capitalism, New York-London: Verso, 2006.

HARVEY, D. Los espacios del capitalismo global. Revista Espacios, Buenos Aires: No 35, Facultad de Filosofía y Letras de la Universidad de Buenos Aires, 2007, p. 20-32.

LEFÈBVRE, H. O direito à cidade. São Paulo: Centauro Editora, 2006.

LINDÓN, Alicia. La modernidad y la subjetividad social: una aproximación a la vida metropolitana. En Aguilar, M.A. y Bassols, M. (coords.) La dimensión múltiple de las ciudades. México DF: UAM, 2001.

LUDEÑA URQUIZO, W. Lima. Ciudad y globalización: paisajes encontrados de fin de siglo. En El desafío de las Áreas Metropolitanas en un mundo globalizado. Una mirada a Europa y América Latina. Actas del Seminario Internacional junio 2002. Barcelona: Institut Catalá de Cooperació Iberoamericana, 2003.

LUDEÑA URQUIZO, W. Lima, ciudad y Globalización. Paisajes encontrados de fin de siglo. En Ludeña Urquizo, W., Urbanismo dixit. Quito: Inquisiciones, Olacchi, 2009.

MIGNAQUI, Iliana y SZAJNBERG, Daniela. Tendencias en la organización del espacio residencial en la región metropolitana de Buenos Aires en los noventa. In Bertoncello, Rodolfo y Alessandri Carlos, Ana Fani (Compiladores) Procesos territoriales en Argentina y Brasil. Buenos Aires: Instituto de Geografía, Facultad de Filosofía y Letras, Univer- sidad de Buenos Aires, 2003, p. 91-115.

POMA, Lucio. La nueva competencia territorial. In Boscherini, F. y Poma, L (compiladores) Territorio, conocimiento y competitividad. El rol de las instituciones en el espacio global. Buenos Aires: Miño y Dávila Editores, 2000, p. $39-76$.

PRÉVÔT SCHAPIRA, M. F. Buenos Aires, en los años '90: metropolización y desigualdades. EURE (Santiago). Vol 28, no. 85, p. 31-50, dic. 2002.

RIBEIRO, L. C. Q. Metropolização, segmentação sócioespacial e acumulação urbana: as forças da questão social no Rio de Janeiro. En El desafío de las Áreas Metropolitanas en un mundo globalizado. Una mirada a Europa y América Latina. Actas del Seminario Internacional, junio 2002. Barcelona: Institut Catalá de Cooperació Iberoamericana, 2003.

SANTOS, Milton. A aceleração contemporânea: tempo- -mundo e espaco-mundo In Santos, M. et al. (Org.) O Novo Mapa do Mundo. Fim de século e globalização. São Paulo: Hucitec-Anpur, 1993, p. 15-22.

SANTOS, Milton. O retorno do território- In Santos, M. et all (org.) Território. Globalização e Fragmentação, São Paulo: Hucitec, 1994, p. 15-20.

SANTOS, Milton. A natureza do espaço. Ténica e tempo. Razão e emoção. São Paulo: HUCITEC, 1996.

SASSEN, Saskia. Sociología de la globalización. Bue- nos Aires: Katz Editor, 2007.

SENNETT, R. La cultura del capitalismo. Barcelona: Anagrama, 2006.

VAINER, C. Patria, Empresa e Mercadoria. Notas sobre a estrategia discursiva do Planejamento Estratégico Urbano. Arantes, O.; Vainer, C.; Maricato, E. (Org). A cidade do pensa- mento único: desmanchando consensos. Petrópolis: Vozes, 2000, p . 75-103.

VELTZ, Pierre. Mondialisation, Villes et Territoires. L' Économie d'Archipel. Paris: Presses Universitaires de France, 1996. 